\title{
Market Coupling and the CWE Project
}

\author{
Alexander Weber · Dietmar Graeber • Andreas Semmig
}

Published online: 27 October 2010

(C) The Author(s) 2010. This article is published with open access at Springerlink.com

\begin{abstract}
The article copes with the ongoing effort to establish implicit auctions to allocate transmission capacity on cross-border interconnectors in the power grid. By the means of implicit auctions (in contrast to explicit auctions), cross-border capacities are included in the clearing of local power exchanges. Concerning the day ahead auction, 'market coupling' plays an important role. Market coupling connects (formerly often national) electricity markets, simplifying cross-border trade. One of the main drivers of market coupling projects is the pursuit of European market integration i.e. allowing for convenient cross-border trade. The other reason is the perception that explicit auctions of transmission capacity (in addition to energy auctions which are often performed later) do sometimes lead to sub-optimal results. The objective function of market coupling is the maximisation of total welfare of all connected markets. Further to the explanation of different market coupling models (also regarding capacity calculation), the current development in Europe is wrapped up-including the CWE market coupling (Central Western Europe) project. The CWE market coupling is announced to start in fall 2010, coupling the day-ahead electricity markets of Belgium, France, Germany, Luxembourg and the Netherlands.
\end{abstract}

\section{Market Coupling und das CWE-Projekt}

Zusammenfassung Der vorliegende Artikel beschäftigt sich mit aktuellen Bestrebungen zur impliziten Bewirtschaftung von Grenzkuppelstellen im Stromnetz. Durch implizite Auktionen (im Gegensatz zu expliziten Auktionen) wer-

A. Weber $(\varangle) \cdot$ D. Graeber · A. Semmig

EnBW Transportnetze AG, Kriegsbergstr. 32, 70174 Stuttgart,

Germany

e-mail: alex.weber@enbw.com den Grenzkuppelkapazitäten automatisch im Rahmen der Markträumung (Marktpreisbestimmung) lokaler Strombörsen berücksichtigt. Dabei spielt bezüglich der vortäglichen Spotauktion (,day ahead“) insbesondere das so genannte Market Coupling eine bedeutende Rolle. Im Rahmen des Market Coupling werden (vormals häufig) nationale Strommärkte so verbunden, dass der grenzüberschreitende Handel vereinfacht wird. Der Grund hierfür ist einerseits der politische Wunsch nach einer europäischen „Marktintegration" als auch die Beobachtung, dass explizite Auktionen von Übertragungskapazität (zusätzlich zu zeitlich häufig anders gelagerten Spotauktionen für Energie) tendenziell zu suboptimalen Allokationen führen. Zielfunktion der Grenzkuppelstellenbewirtschaftung ist im Rahmen des Market Coupling die Maximierung der Wohlfahrt aller derart verbundenen Märkte. Im Rahmen des Artikels werden grundsätzliche Arten des Market Coupling - auch bezüglich der Kapazitätsberechnung - erläutert sowie ein kurzer Überblick über die derzeitig in Europa umgesetzten Coupling-Projekte gegeben. Dabei wird auch auf das CWE-Market-Coupling (Central Western Europe) eingegangen, das im Herbst 2010 zwischen Belgien, Deutschland, Frankreich, Luxemburg und den Niederlanden starten soll.

\section{Introduction}

The European electricity market is subject to integration efforts with the long term aim of building a single electricity market (alternatively: internal electricity market-IEM). Today's integration efforts are especially focusing on congestion management at cross border interconnections: these are the power lines connecting (most often national) electricity market areas. Historically, these electricity market areas relate to one or multiple TSO-areas, therefore the term 
'cross border' interconnections is often used to denominate congested lines between price resp. market areas. Since EC Regulation 1228/2003 on "network access for cross border exchanges" stipulated the use of "non-discriminatory market based solutions", which "should give economic signals to the market participants and transmission system operators involved" there have been ongoing efforts to address the problem of scarce cross border capacities. This led to a steady development of congestion management methods. Nowadays, the large majority of interconnector capacity in Europe is allocated on a yearly, monthly and day-ahead basis. The day-ahead allocation is often conducted via explicit auctions. The gate-closure times of these auctions are usually some hours before the gate-closure times of the organized day ahead markets. In general, explicit auctions fulfil the requirement of EC 1228/2003. Considering the results of the organized day-ahead power exchange markets, sometimes flows from a high price area to a low price area can be observed. Those are called 'adverse flows'. Such adverse flows can be interpreted the way that the parties involved were not able to predict prices in the connected regions properly (otherwise they would not have paid for capacity just to loose money).

This is for example demonstrated by Dieckmann (2008) who ran a least square regression analysis against historical power price spreads and auction results for transmission capacity on the border between the Netherlands and Germany. Her OLS linear regression analysis on an hourly basis for the year 2007 yields an impressively weak relation of roughly 0.08 between power price spreads and prices for transmission capacity.

Another example of inefficiencies under explicit auctions is given by Böttcher (2008) who gives an estimate of observed adverse flows to be in the range of $20 \%$ to $30 \%$ on interconnectors at the Danish-German border when auctioned explicitly.

An adequate measure to improve this capacity allocation mechanism is to introduce implicit auctions where capacity is allocated implicitly within the clearing of the energy markets and market participants do not have to cope with price predictions for arbitrage between market areas. Rationales, mechanisms and organisation of implicit auction mechanisms for the allocation of scarce interconnector capacities are exhibited in the next chapter.

An overview of abbreviations that are often used in the context of market coupling is given in a concluding table at the end of the article (Table 1).

\section{Basics and Applications of Market Coupling}

Let's start with an example: be A and B two interconnected electricity market areas with accordingly different supply/demand curves and therefore different prices (Fig. 1a).
Region A

Region B

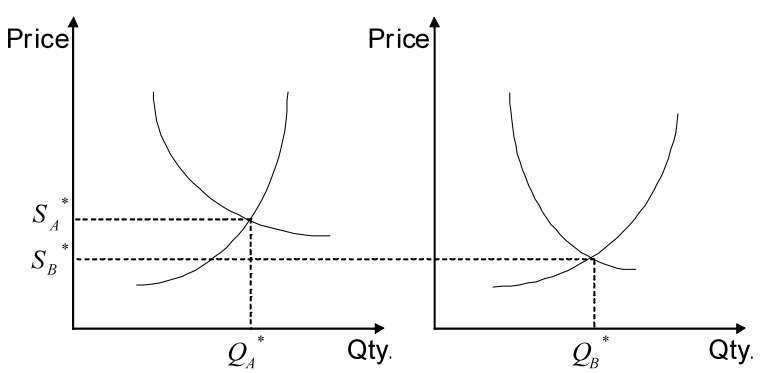

a) Regions $A$ and $B$ are isolated and do not exchange electricity.

Region A

Region B

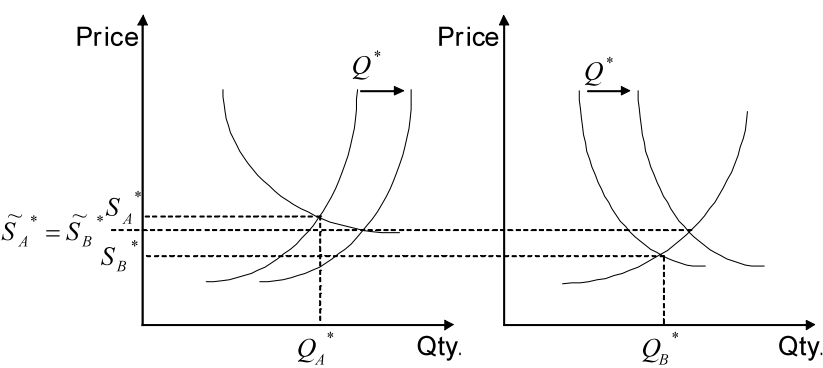

b) Regions $A$ and $B$ are connected; there is sufficient interconnector capacity available so that prices in both regions are equalized.

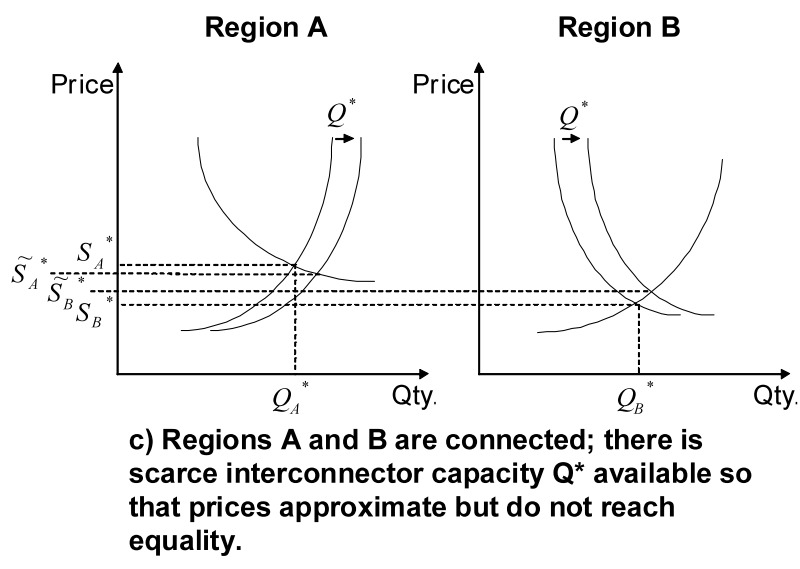

Fig. 1 Supply and demand curves in isolated and connected electricity markets (Source: EnBW Transportnetze AG)

Until now, the interconnector is not used since both markets are in their local equilibrium. However, such a situation offers an arbitrage opportunity, namely to buy electricity in Region B (where the price $S_{\mathrm{B}}^{*}$ is lower than the price $S_{\mathrm{A}}^{*}$ in region $\mathrm{A}$ ) and sell it to region $\mathrm{A}$. Under perfect competition, this would happen until prices in regions $\mathrm{A}$ and $\mathrm{B}$ are equal or interconnector capacity is exhausted. The prices for the case where the interconnector is used are denoted as $\tilde{S}_{\mathrm{A}, \mathrm{B}}^{*}$. Figure $1 \mathrm{~b}$ shows the case where interconnector capacity is used and where it is not scarce: then, prices in both regions are equal $\left(\tilde{S}_{\mathrm{A}}^{*}=\tilde{S}_{\mathrm{B}}^{*}\right)$. If the interconnector capacity available is not sufficient to equalize prices in both regions, a price dif- 
ference will remain: $\tilde{S}_{\mathrm{A}}^{*} \neq \tilde{S}_{\mathrm{B}}^{*}$ (see Fig. 1c). This price difference (multiplied with the transfer capacity) is then called 'congestion rent' (cf. Stoft 2002). It is the economic value of the interconnector for this specific hour when it is a scarce resource.

As discussed before, leaving the task of allocating interconnector capacity to the market (in the sense of using at least 3 different auctions, at least one for capacity and two for day-ahead markets, each with different gate-closure times and therefore inconsistent expectations), does often not lead to optimal (or even 'good') allocation decisions. The reason for this is uncertainty in expectations: electric power prices are very volatile in nature and thus is the spread between two power prices an arbitrager would have to estimate in order to express his valuation for cross border capacity between those market areas. As already mentioned, capacity auctions are usually done some hours before closing of the electricity market auctions. This increases the uncertainty the trader has when valuing transmission capacity (which he has to do before submitting his bid).

To improve this mechanism, implicit auctions can be used-meaning that cross-border capacity is allocated implicitly within the auctioning of energy in the interconnected electricity markets. Therefore trading electricity becomes less complex, the aforementioned inefficiencies are avoided and scarce interconnector capacity is used more economically. The main terms used to describe the implementation of implicit auctions are 'market splitting' and 'market coupling'. The definitions for the two approaches found in the literature (cf. ETSO 2001a; Grimm et al. 2008; Dieckmann 2008) vary, but market splitting is used to describe a market operated by a single power exchange, whereas market coupling refers rather to a co-operation of multiple power exchanges.

Under both set-ups, the market participants simply place their bids on the respective market, if necessary including a related area. The clearing of the market(s) is then done considering transmission capacity and local bids simultaneously, leading to an optimal allocation.

\subsection{Capacity Calculation}

In a bilateral environment, the market coupling sketched in Fig. 1 is - theoretically - easy to implement. However, today's power grids are highly meshed and coupling projects do often incorporate more than two areas. This is exhibited in Fig. 2: The physical result of withdrawing $100 \mathrm{MW}$ in Region A intending to deliver it in Region B may lead to physical flows totally different from what could have been intuitively expected.

This leads to the insight, that cross-border capacity has to be carefully assessed, it is therefore not possible to offer the full physical capacity of the line to the market. Not only commercial flow

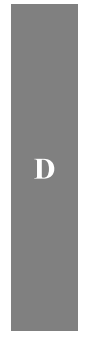

physical flow

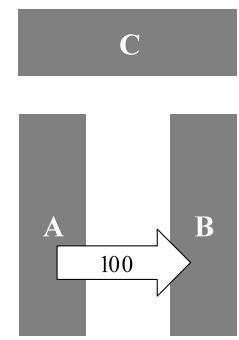

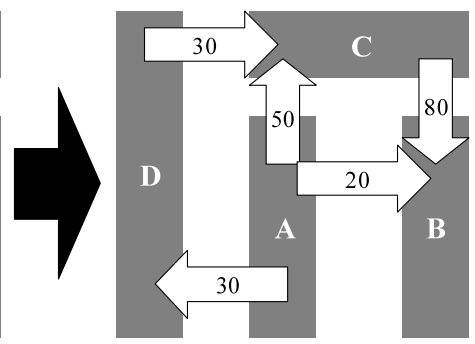

Fig. 2 In highly meshed grids, a commercial flow of 100 MW from Region A to B might lead to a totally counter-intuitive physical result (Source: EnBW Transportnetze AG)

would possible loop flows be neglected, operational security would also be put at stake since some physical capacity is always needed to safely cope with contingencies. The assessment of the capacities which can safely be offered to the market is commonly done by load-flow calculations which assume a "base case" scenario (of plant dispatch and consumption). Then, production is shifted from one region to another to examine whether operational security can still be guaranteed in that case. The maximum value not affecting static system security is then reduced by a reliability margin to cope with loop flows and contingencies. The result is the NTC (net transfer capacity) and represents the maximum capacity that can be offered to the market. Considering that interconnector capacity is often allocated in different auctions (usual scheme: yearly, monthly and daily auctions), the available transfer capacity ATC is calculated by subtracting the already allocated capacity (AAC):

$\mathrm{ATC}=\mathrm{NTC}-\mathrm{AAC}$.

This calculation scheme (ETSO 2001b) can be considered as current standard. However, many cross border capacities are nowadays assessed bilaterally, using profiles including multiple borders (e.g. 'German C', 'Swiss Roof', 'Italian Roof'; cf. EnBW 2009 and Duthaler 2007).

A different capacity calculation method than the ATCapproach is the so-called flow-based method. It incorporates the use of power transmission distribution factors (PTDFs) which reflect the changes in physical flows induced by production shifts between regions. For example, the flows in Fig. 2, induced by a production increase of $100 \mathrm{MW}$ in Region $\mathrm{A}$ and a corresponding decrease of $100 \mathrm{MW}$ in Region $\mathrm{B}$ would have been properly predicted by the use of PTDFs. Yet, flow-based scenarios are very complex and their ability to improve overall welfare heavily depends on the quality of grid models used. For further discussion, see Dieckmann (2008), Duthaler (2007). 


\subsection{Market Coupling as an Optimisation Problem}

Market Coupling can be formulated as an optimisation problem. The objective is then to maximise overall welfare. Welfare is defined as the cumulated differences between the willingness to pay and the accepted prices asked as revealed during the bidding process. Following Meeus et al. (2009), the problem (without considering that commercial flows can be different than physical flows) can be written as:

$$
\max _{q} \sum_{r \in R}\left[\sum_{i \in I_{r}} q_{i} P_{i}-\sum_{j \in J_{r}} q_{j} P_{j}\right]
$$

s.t.

$\sum_{i \in I_{r}} q_{i}-\sum_{j \in J_{r}} q_{j}-\sum_{r_{e x} \in R \backslash r} E_{r, r_{e x}}=0 \quad \forall r \in R$,

$E_{r, r_{e x}} \leq \operatorname{Cap}_{r, r_{e x}} \quad \forall r, r_{e x}$,

$q_{i} \leq Q_{i} \quad \forall i$,

$q_{j} \leq Q_{j} \quad \forall j$,

where $r \in R$ are the regions considered, $i \in I_{r}$ the demand bids in Region $r, j \in J_{r}$ the supply bids in Region $r$ and $P_{i, j}, Q_{i, j}$ the related prices and quantities. The quantities accepted are denominated by $q_{i, j}$. The maximum transfer capacity between two Regions $r, r_{e x}$ is given by $\mathrm{Cap}_{r, r_{e x}}$, the actually used capacity is given by $E_{r, r_{e x}}$. The solution of this optimisation problem yields an optimal usage of the interconnector capacities. Prices can then be computed by considering the prices of the last bids (e.g. highest for supply bids, lowest for demand) accepted in each region. However, the formulation given above is a strong simplification: block-orders (i.e. bids covering multiple hours) which are widely used among European power exchanges are neglected. Because those bids cannot be partly accepted, the given linear problem becomes a mixed integer linear problem which is NP-hard and poses a computational challenge, especially if the coupling algorithm is subject to real-time constraints. Real-time constraints means: The system must deliver a result before a given deadline. In market coupling applications, this is due to subsequent processes following the clearing of the markets such as validation of schedules by the transmission system operators (TSOs) involved.

\subsection{Practical Aspects of Market Coupling}

As already touched on in the explanation of market coupling and market splitting, organizational aspects of market coupling solutions play an important role: As European power markets cannot be designed 'from the scratch', market integration efforts have to build on the existing structure. Therefore, different market coupling models exist. The most integrated one is "price market coupling" (or "price coupling").
In a price coupling approach, both prices and flows are computed centrally by the coupling algorithm. This means that the power exchanges of the regions involved do not set prices but just forward bids to the coupler and receive prices (and volumes) in return. If price calculation shall remain a power exchange task, volume coupling is an option. In volume coupling, only flows are calculated based on the bids received from the exchanges. The difference between price and volume coupling is thus whether the price calculation is done centrally (price coupling) or decentrally (volume coupling). In the latter case, price calculation can be kept at the power exchanges. The power exchanges then receive unlimited bids calculated by the volume coupler. Depending on how exact the volume coupler simulates the clearing process of the involved power exchanges, the volume coupling is called 'loose' or 'tight' (EuroPEX, ETSO 2009).

The situations that are more likely to occur with loose coupling than with tight coupling are not necessarily adverse flows, but such that the transmission capacity may not be fully utilised even though the local power exchange prices are different.

However, the exclusive use of capacity by a central coupling algorithm makes this algorithm a monopoly function with respect to the allocation of cross-border capacity. This is true for both volume and price coupling. Thus with market coupling, the access to interconnector capacity is discriminatory in the sense that it is offered exclusively to the coupled power exchanges. This is in contrast to EC 1228 (2003) which requires a "non-discriminatory" access to capacity.

Therefore, to keep the market for power exchanges contestable, new entry to the coupling mechanism should be kept possible. Otherwise, this would pave the way to 'cartelize the supply of trading services and to monopolize the operation of trade across borders' (Meeus 2010). This implies that the operation of the central coupling mechanism would require some kind of regulatory control in order to keep the 'supply of trading services' (i.e. the power exchanges' business) contestable.

Besides that, difficulties arise because of parallel coupling initiatives starting to overlap: two regions operating their own coupling algorithm can in general not be "connected" (cf. E-Bridge 2009). Often, different approaches were used to implement the respective coupling solutions which makes them incompatible (both technical and governance issues). In such cases, 'disassembling' the established processes and building a new, central solution often seems difficult and costly. A possible solution is the installation of a so-called "dome" coupler (Fig. 3). A dome coupler receives the aggregated bids of all involved market areas. Those market areas are already coupled by separate regional market coupling systems. Then, the dome coupler calculates unlimited bids between the areas which are physically interconnected, but whose interconnectors are not covered by the 


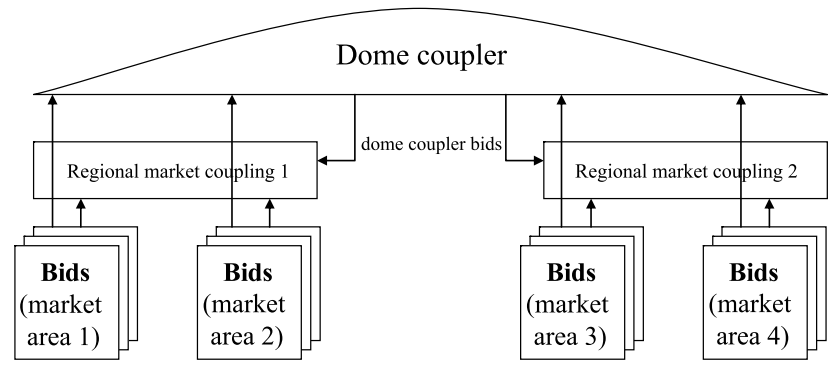

Fig. 3 Dome coupling is a volume coupler coupling multiple, already existing coupling systems (Source: EnBW Transportnetze AG)

regional market coupling systems. This requires the dome coupler to mimick the already installed coupling systems as exact as possibly, since only then the calculated bids of the dome coupler can sufficiently contribute to overall welfare maximisation. (EuroPEX, ETSO 2009). Since the dome coupler only generates (unlimited) bids and leaves price determination to the regional/local entities, dome coupling is necessarily volume coupling.

The issues discussed above underline the need for a coordinated institutional and legal framework. A short summary of the discussions and results between the European Commission, regulators and TSOs is given in the next chapter.

\section{Current Development and Perspectives in Europe and CWE MC}

The official, long-term target model is a single, day-ahead price coupling all over Europe. To speed up this development, the so-called 'electricity regional initiative' (ERI) was set up in spring 2006 by the ERGEG (European Regulator's Group for Electricity and Gas). The rationale behind this was to establish integrated regional markets as a starting point for building the IEM. These regional initiatives are:

- Baltic (Baltic States-BS): Estonia, Latvia, Lithuania

- Central East (CEE): Austria, Czech Republic, Germany, Hungary, Poland, Slovakia, Slovenia

- Central South (CSE): Austria, France, Germany, Greece, Italy, Slovenia

- Central-West (CWE): Belgium, France, Germany, Luxembourg, Netherlands

- Northern: Denmark, Finland, Germany, Norway, Poland, Sweden

- South-West (SWE): France, Portugal, Spain

- France, UK, Ireland (FUI): The electricity market of Ireland is denoted as single electricity market (SEM) since it encompasses the Republic of Ireland and Northern Ireland.

Currently, 4 cross-country-border coupling projects are at operation in Europe. Those are:
- A market splitting solution in Portugal and Spain (Mercado Ibérico de Electricidade-MIBEL),

- A market splitting solution for Denmark, Finland, Sweden, Norway, operated by Nordpoolspot,

- A price market coupling solution for the Netherlands, Belgium and France (TLC - tri-lateral coupling) operated by the power exchanges of the three countries,

- Volume market coupling between Germany and Denmark + Sweden, operated by EMCC.

An outline, how the long-term target could be reached was given by the PCG ${ }^{1}$ at the 17th Florence Forum in December 2009 (Fig. 4). The abbreviations used in the figure are the same as given above. The figure shows a possible schedule for coupling electricity markets of the EU. Both the average yearly consumption of the markets and the interconnector capacities illustrate the coupling potential resulting in a single coupled market of $>3500$ TWh yearly consumption.

The PCG was then superseded by the AHAG, the adhoc advisory group, which was set up by the 17th Florence Forum. The tasks of AHAG are to support ERGEG in the development of so-called framework guidelines (FG) stipulated by the 3rd legislative package on EU electricity \& gas markets. The third package focuses on the integration of the IEM and therefore cross-border issues. The implementation of the third package shall be implemented by the following interaction of regulators and concerned network operators: the regulators will collaborate within ACER (Agency for the Cooperation of Energy Regulators, EC 713/2009) - the corresponding organisation for the electricity TSOs is ENTSOE (European Network of Transmission System Operators for Electricity, EC 714/2009). For implementation, ACER will prepare specific framework guidelines which ENTSO-E will then use to define Network Codes (NC). These Network codes will then be approved by ACER, likely followed by public consultations. The planned structure and schedule on FGs and NCs is documented in the 3-year-Plan ("3a-Plan") by the High Level Group (composed of EC, both ENTSOs and ERGEG) which was presented at the 18th Florence Forum. The timeframe envisaged by the plan are the years 2010-2012. Among the FGs which are all related to crossborder topics, the FG "on capacity allocation and congestion management" seems to have the most impact on market

\footnotetext{
${ }^{1}$ PCG stands for 'Project Coordination Group' which was established in the aftermath of the 15th Florence Forum, held in November 2008. It was chaired by the European Regulators' Group for Electricity and Gas (ERGEG) and included participants from various stakeholders, including European power exchanges and TSOs. Its job was to propose a target model to integrate the regional European electricity markets. For further information, please see: http://www.energy-regulators.eu/portal/page/portal/EER_HOME/ EER_WORKSHOP/Stakeholder\%20Fora/Florence\%20Fora/PCG.
} 


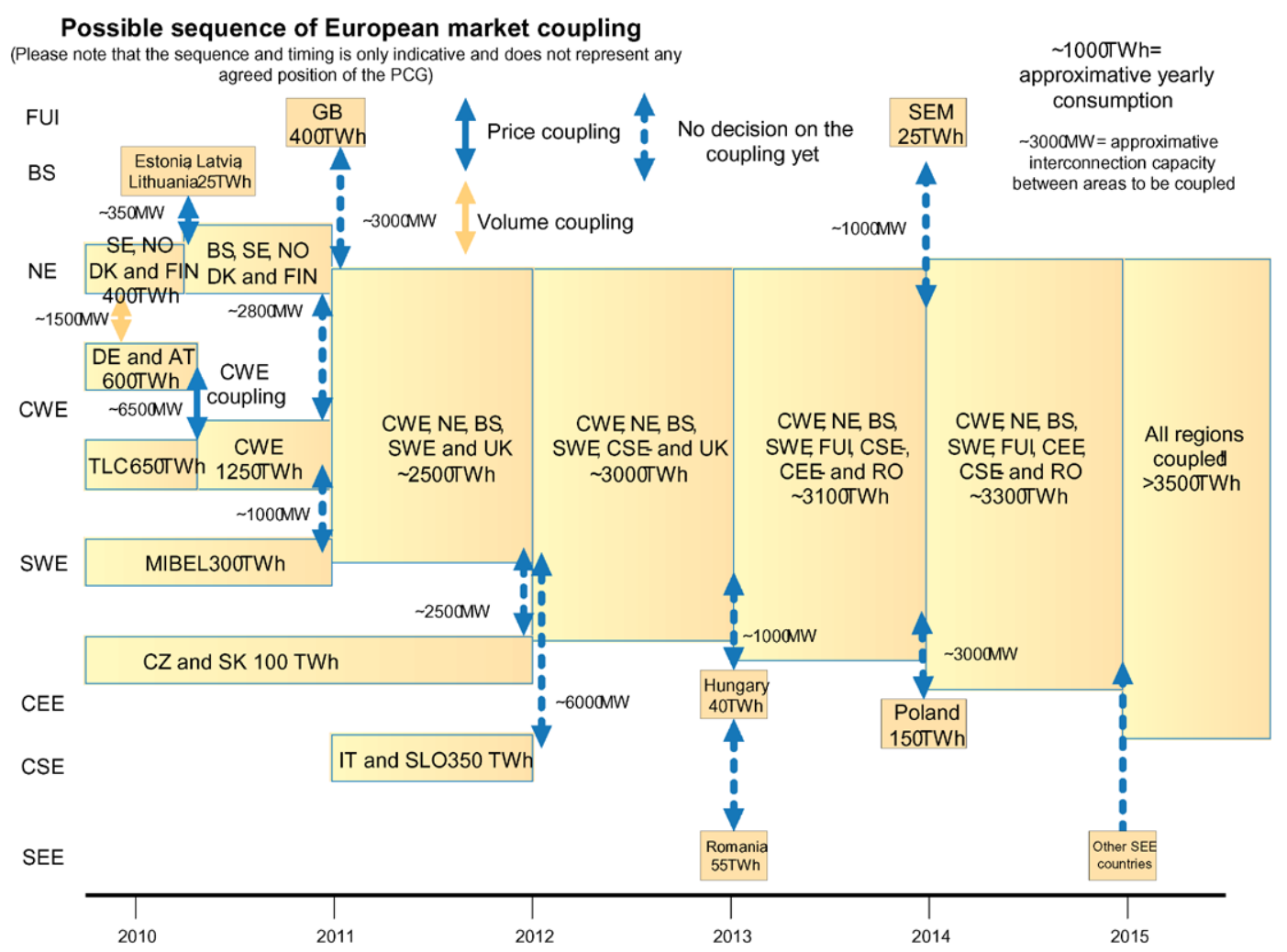

Fig. 4 Possible evolution of market coupling in Europe. Source: PCG

coupling activities and are also approached very early compared to other activities of the 3a-Plan. Other FGs cover grid connection, balancing, third party access etc. The aforementioned FG foresees $4 \mathrm{NCs}$ :

1. Capacity Calculation,

2. ID platform (trading + congestion management),

3. DA (trading + congestion management) and

4. Forward markets.

This FG shall benefit directly from AHAG work which has project groups on capacity calculation, intraday trading and day-ahead market coupling governance. The overall package implementation process then hopefully leads to a harmonized European framework for market integration projects: A standard set-up of common technical and governance rules which have been shown to be difficult and timeconsuming to create within single projects.

\subsection{The CWE MC Project}

The next coupling project launch foreseen is CWE/Nordic (see press release by CWE members of 7 April 2010 and common press release by CWE, EMCC and Nordic parties of 29 July 2010). It is planned to start with ATCbased price coupling between CWE members combined with an 'interim tight volume coupling' (ITVC) to include the Nordic region. The project will introduce a day ahead price coupling for Belgium, France, Germany, Luxembourg and the Netherlands. Three power exchanges (APX, Belpex and EPEXSpot) and 6 transmission system operators are involved in the project (Amprion, Creos, Elia, EnBW TNG, RTE and TenneT). In course of the coupling, the gateclosure times of all concerned day-ahead markets of the power exchanges involved will be moved to $12.00 \mathrm{~h}$.

The interim tight volume coupling will be provided by EMCC who today already operate the volume coupling solution between the Nordic region and Germany. The daily coupling process will then have the following sequence:

1. simultaneous gate-closure of all power exchanges.

2. Calculation of bids (volume coupling) by EMCC, considering the behaviour of the CWE coupling algorithm.

3. Calculation of the CWE price coupling solution, submission of results to coupled power exchanges.

For the CWE price coupling, it is planned to test flow-based coupling in parallel to the ATC operation and to analyse the results. The project members will then jointly decide on a switch to flow-based (Chouteau and Bourdon 2010).

In parallel to the ongoing CWE/Nordic process, an ENTSO-E project on the NWE (=CWE/Nordic) "Enduring Solution" has already been set up. This project aims at developing an enduring price coupling solution for the NWE region. 
Table 1 Market-coupling related terms

\begin{tabular}{ll}
\hline Abbreviation & Explanation \\
\hline ATC & Available Transfer Capacity \\
DAM & Day-Ahead Market \\
GCT & Gate Closure Time \\
IEM & Internal Electricity Market \\
PTDF & Power Transfer Distribution Factor, approach to \\
& implement flow-based market coupling \\
PX & Power Exchange \\
TSO & Transmission System Operator \\
\hline
\end{tabular}

\section{Challenges and Conclusion}

Although the basic idea of market coupling is simple, the devil is in the details: coupling does not only require the harmonization of gate-closure times of the power exchanges involved, it also leads to widespread regulatory, legal and technical questions. This is even more true, the more stakeholders are exposed to the coupling. Therefore, coordination and political issues become more and more important besides the technical challenges. However, market coupling approaches can be considered as appropriate means towards the IEM and the current projects are promising. Besides the general coordination issues mentioned above, a severe concern is with the changes implied by the introduction of central algorithms, which allow for a potential of forming market power. Therefore, the institutional arrangement of a central coupling algorithm and the trading platforms (power exchanges) is crucial.

Open Access This article is distributed under the terms of the Creative Commons Attribution Noncommercial License which permits any noncommercial use, distribution, and reproduction in any medium, provided the original author(s) and source are credited.

\section{References}

Böttcher E (2008) Market coupling on the German-Danish interconnectors-Interim status of temporary suspension. Presentation of EMCC at 4th Stakeholder Group Meeting, 5 November 2008 København. Available online: http://www.ergeg.org/portal/ page/portal/EER_HOME/EER_INITIATIVES/ERI/Northern/ Meetings1/SG_meetings/4supthsup\%20Northern\%20SG/AD/ 5B78D91C2F313DD7E040A8C03C2F3B8E

Chouteau S, Bourdon S (2010) Harmonization of cross border transmission capacity allocation within the Central West Europe region. In: CIGRE 2010
CWE (2010) Launch of CWE market coupling proposed on 7 September. Press release of 7 April 2010. Available online: http://www. enbw.com/content/en/press/press_releases/2010/04/PM_ 20100407_CWE_cu_mw01/20100417_CWE-MC_EN_v0_2.pdf

CWE/Nordic (2010) CWE/Nordic coupling joint target launch date. Press release of 29 July 2010. Available online: http://www.enbw. com/content/de/presse/pressemitteilungen/2010/07/PM_

20100729_CWE_tng_mw01/20100729_final_press_release_ CWE-ITVC_TNG-Vorlage.pdf

Dieckmann B (2008) Engpassmanagement im Europäischen Strommarkt. Inauguraldissertation, Westfälische Wilhelms-Universität Münster. Available online: http://miami.uni-muenster.de/servlets/ DerivateServlet/Derivate-4797/diss_dieckmann.pdf

Duthaler C (2007) Power transfer distribution factors: analyse der Anwendung im UCTE-Netz. Master thesis, ETH Zurich. Available online: http://documents.epfl.ch/users/d/du/duthaler/www/0708_ ptdf-duthaler.pdf

E-Bridge (2009) Analysis of coupling solutions for the CWE region and the Nordic market. Available online: http://www.e-bridge.de/ index.php?id=61\&L=1\&tx_ttnews\%5Btt_news\%5D=127\&tx_ ttnews $\% 5$ BbackPid $\% 5 \mathrm{D}=64 \& \mathrm{cHash}=\mathrm{fa} 2 \mathrm{~d} 742 \mathrm{~b} 97$

EC (2003): REGULATION (EC) No 1228/2003 on conditions for access to the network for cross-border exchanges in electricity. Available online: http://eur-lex.europa.eu/LexUriServ/ LexUriServ.do?uri=OJ:L:2003:176:0001:0010:EN:PDF

EnBW Transportnetze AG (2009) Allgemeines Modell zur Berechnung der Gesamtübertragungskapazität und der Sicherheitsmarge der EnBW Transportnetze AG. Available online: http://www. enbw.com/content/de/netznutzer/media/pdf/Allgemeines_ Kapazit_tsberechnungsmodell.pdf

ETSO (2001a) Definitions of transfer capacities in liberalised electricity markets. Final Report. Available online: http://www.entsoe.eu/ fileadmin/user_upload/_library/ntc/entsoe_ transferCapacityDefinitions.pdf

ETSO (2001b) Position paper on congestion management. Florence Forum, May 7th \& 8th, 2001. Available online: http://www. entsoe.eu/fileadmin/user_upload/_library/publications/etso/ Congestion_Management/Position_Paper_on_Congestion_ Management.pdf

EuroPEX, ETSO (2009) Development and implementation of a coordinated model for regional and inter-regional congestion management. Available online: http://www.borzen.si/dl/EuroPEXETSO_report-25-02-09.pdf

Grimm V, Ockenfels A, Zoettl G (2008) Strommarktdesign: Zur Ausgestaltung der Auktionsregeln an der EEX. Z Energiewirtsch 32(3):147-161. doi:10.1007/s12398-008-0020-7

Meeus L (2010) Why (and how) to regulate power exchanges in the EU market integration context? EUI Working Papers. RSCAS 2010/12. Robert Schuman Centre for advanced Studies, Florence School of Regulation. Available online: http://cadmus.eui.eu/ dspace/bitstream/1814/13515/1/RSCAS_2010_12.pdf

Meeus L, Vandezande L, Cole S, Belmans R (2009) Market coupling and the importance of price coordination between power exchanges. Energy 34(2009):228-234. doi:10.10106/j.energy.2008. 04.013

Stoft S (2002) Power system economics: designing markets for electricity. Wiley-Interscience/IEEE Press, Piscataway 